\title{
Ansalactams B-D Illustrate Further Biosynthetic Plasticity within the Ansamycin Pathway
}

\author{
Tu Cam Le,,$^{\dagger}$ Inho Yang, ${ }^{\dagger}$ Yeo Joon Yoon, ${ }^{\dagger}$ Sang-Jip Nam, ${ }^{* \dagger}$ and William Fenical $* *$
}

\section{${ }^{\dagger}$ Department of Chemistry and Nano Science, Global Top 5 program, Ewha Womans University, Seoul 03760, Korea}

${ }^{\ddagger}$ Center for Marine Biotechnology and Biomedicine, Scripps Institution of Oceanography, University of California-San Diego, La Jolla, CA920930204 


\section{Table of Contents}

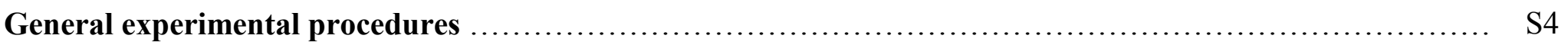

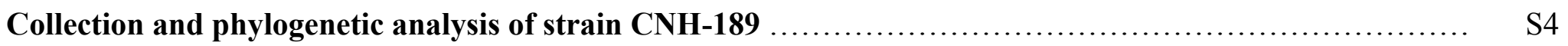

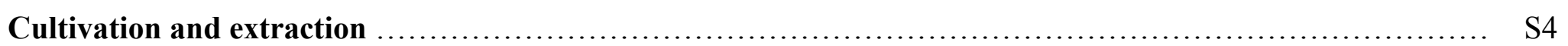

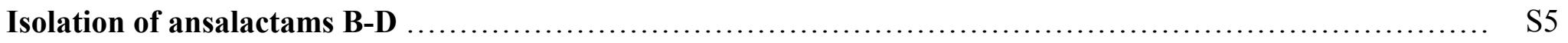

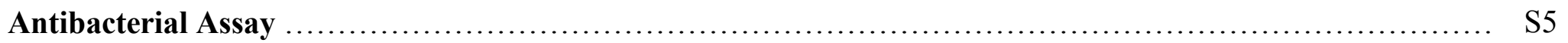

Table S1. NMR spectral data for ansalactams B (1), C (2), and D (3) in methanol- $d_{4} \ldots \ldots \ldots \ldots \ldots \ldots \ldots \ldots \ldots \ldots . . . \ldots \ldots$

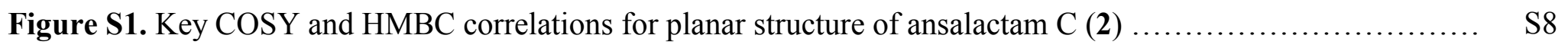

Figure S2. Key ROESY correlations for determination of the relative stereochemistry of 2 (a) and 3 (b) ... $\quad$ S9

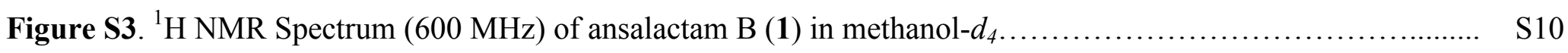

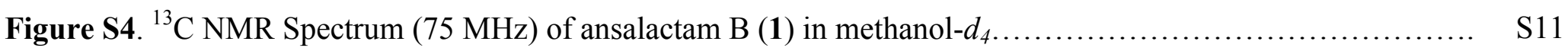

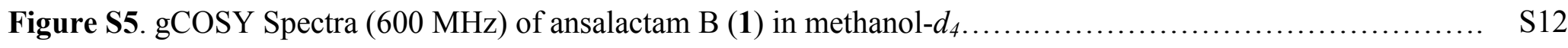

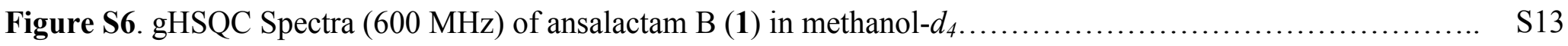

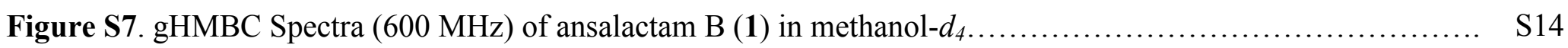

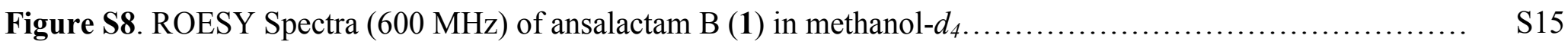

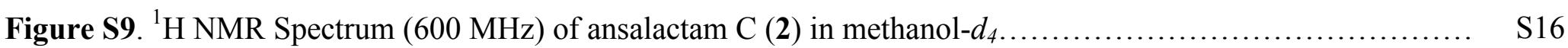

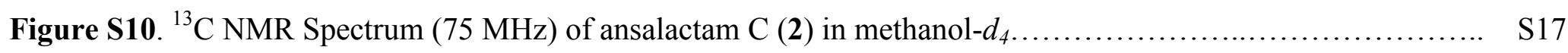




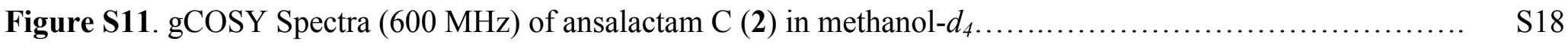

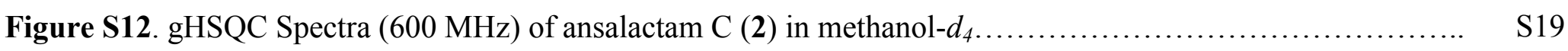

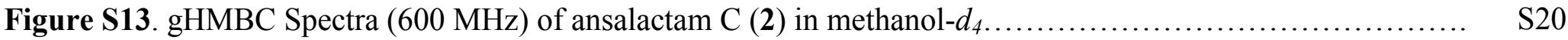

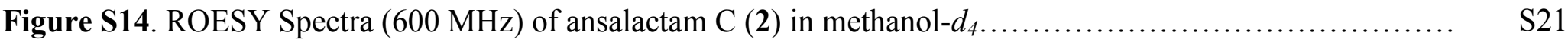

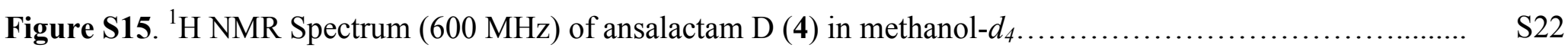

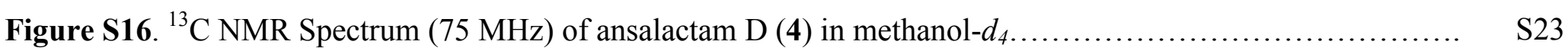

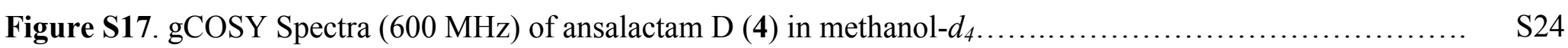

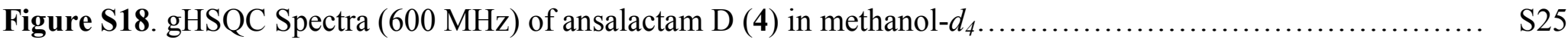

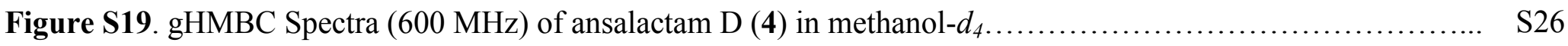

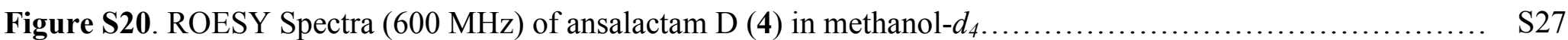

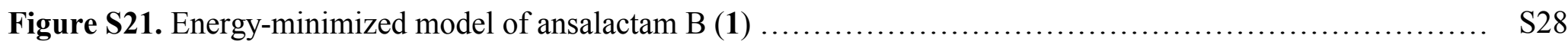

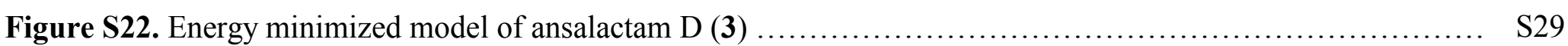


General experimental procedures. The optical rotations were measured using a Rudolph Research Autopol III polarimeter with a 10-cm cell. UV spectra were recorded in a Varian Cary UV-visible spectrophotometer with a path length of $1 \mathrm{~cm}$ and IR spectra were recorded on a PerkinElmer 1600 FT-IR spectrometer. ${ }^{1} \mathrm{H}$ and 2D NMR spectra data were recorded at $500 \mathrm{MHz}$ in methanol- $d_{4}$ solution containing Me $\mathrm{Si}$ as internal standard on Varian Inova spectrometers. ${ }^{13} \mathrm{C}$ NMR spectra were acquired at $75 \mathrm{MHz}$ on a Varian Inova spectrometer. High resolution ESI-MS spectra were measured on a JEOL, JMS-AX505WA mass spectrometer. Low resolution LC/MS data were measured using a Hewlett-Packard series $1100 \mathrm{LC} / \mathrm{MS}$ system with a reversed-phase $\mathrm{C}_{18}$ column (Phenomenex Luna, $4.6 \mathrm{~mm} \times 100 \mathrm{~mm}, 5 \mu \mathrm{m}$, flow rate of $0.7 \mathrm{~mL} / \mathrm{min}$ ).

Collection and phylogenetic analysis of strain CNH-189. The actinobacterium (strain CNH189) was isolated from a nearshore marine sediment collected off Oceanside, California and 16S rRNA gene sequence analysis indicated a Streptomyces sp. (accession number HQ214120).

Cultivation and extraction. The bacterium (strain CNH189) was cultured in sixty $2.8 \mathrm{~L}$ Fernbach flasks each containing $1 \mathrm{~L}$ of a natural seawater-based medium (10 g starch, $4 \mathrm{~g}$ yeast extract, $2 \mathrm{~g}$ peptone, $1 \mathrm{~g} \mathrm{CaCO}$, $\left.40 \mathrm{mg} \mathrm{Fe}_{2}\left(\mathrm{SO}_{4}\right)_{3} \bullet 4 \mathrm{H}_{2} \mathrm{O}, 100 \mathrm{mg} \mathrm{KBr}\right)$ and shaken at $230 \mathrm{rpm}$ at $27^{\circ} \mathrm{C}$. After seven days of cultivation, sterilized XAD-16 resin $(20 \mathrm{~g} / \mathrm{L})$ was added to adsorb the organic components and the culture and resin were shaken at $215 \mathrm{rpm}$ for 2 hours. The resin was filtered, washed with deionized water, and eluted with acetone. The acetone was evaporated, and the resulting aqueous layer was extracted with ethyl acetate $(3 \times 500 \mathrm{~mL})$. The ethyl acetate-soluble layer was dried in vacuo to yield $4.5 \mathrm{~g}$ of organic extract. 
Isolation of ansalactams B-D. The organic extract ( $4.5 \mathrm{~g})$ was fractionated by open column chromatography on silica gel (25 g), eluted with a step gradient of dichloromethane and methanol. The dichloromethane/methanol 50:1 fraction contained a mixture of ansalactams, which were further purified by reversed-phase HPLC (Phenomenex Luna C-18 (2), $250 \times 100 \mathrm{~mm}, 2.0 \mathrm{~mL} / \mathrm{min}, 5 \mu \mathrm{m}, 100 \AA, \mathrm{UV}=210 \mathrm{~nm}, \mathrm{H}_{2} \mathrm{O}: \mathrm{CH} \mathrm{C}_{3} \mathrm{CN}=$ 35:65) to afford ansalactams B (2, $5.0 \mathrm{mg}), \mathrm{C}(\mathbf{3}, 6.0 \mathrm{mg}), \mathrm{D}(\mathbf{4}, 2.0 \mathrm{mg})$, and A $(4,70.0 \mathrm{mg})$.

Ansalactam B (1): pale yellow oil; $[\alpha]_{\mathrm{D}}^{21} 107$ (c 0.7, methanol); IR (KBr) $v_{\max } 3402,2955,1684,1567,1277,1031 \mathrm{~cm}^{-1}$; UV (methanol) $\lambda_{\text {max }}$ $(\log \varepsilon) 238(4.3), 278(4.2) \mathrm{nm} ;{ }^{1} \mathrm{H}$ and 2D-NMR (500 MHz, methanol- $\left.d_{4}\right)$, see Table 1; HRESITOFMS [M+H] ${ }^{+} m / z 546.2850\left(\mathrm{C}_{33} \mathrm{H}_{40} \mathrm{NO} 6\right.$, calcd $[\mathrm{M}+\mathrm{H}]^{+}$546.2856).

Ansalactam C (2): pale yellow oil; $[\alpha]_{\mathrm{D}}^{21} 33$ (c 0.05, methanol); IR (KBr) $v_{\max } 3354,2955,1698,1451,1293,736 \mathrm{~cm}^{-1}$; UV (methanol) $\lambda_{\text {max }}$ $(\log \varepsilon) 250(4.5), 295(4.1), 315(3.8) \mathrm{nm} ;{ }^{1} \mathrm{H}$ and 2D-NMR (500 MHz, methanol- $\left.d_{4}\right)$, see Table 2; HRESITOFMS [M+H] ${ }^{+} m / z 564.2945$ $\left(\mathrm{C}_{33} \mathrm{H}_{42} \mathrm{NO}_{7}\right.$, calcd $[\mathrm{H}+\mathrm{H}]^{+}$564.2961).

Ansalactam D (3): pale yellow oil; $[\alpha]_{\mathrm{D}}^{21} 86\left(c 0.3\right.$, methanol); IR (KBr) $v_{\max } 3402,2935,1670,1451,1272 \mathrm{~cm}^{-1} ; \mathrm{UV}$ (methanol) $\lambda_{\max }(\log \varepsilon)$ 250 (4.4), 290 (3.9), $315(3.5) \mathrm{nm} ;{ }^{1} \mathrm{H}$ and 2D-NMR (500 MHz, methanol- $\left.d_{4}\right)$, see Table 2; HRESITOFMS [M+H] ${ }^{+} m / z 546.2852\left(\mathrm{C}_{33} \mathrm{H}_{40} \mathrm{NO}_{6}\right.$, calcd $[\mathrm{M}+\mathrm{H}]^{+}$546.2856).

Antibacterial Assay: Methicillin-resistant Staphylococcus aureus (MRSA) was inoculated in Mueller-Hinton agar media for $24 \mathrm{~h}$ at $37{ }^{\circ} \mathrm{C}$. The bacterial colony was cultivated in a $15 \mathrm{~mL}$ round tube containing $6 \mathrm{~mL}$ of Mueller-Hinton broth media at $37^{\circ} \mathrm{C}$ and $225 \mathrm{rpm}$ for $24 \mathrm{~h}$. Test compounds and a positive control (vancomycin) were dissolved in DMSO and $100 \mu \mathrm{L}$ were added to a 96 -well microtiter plate having $50 \mu \mathrm{L}$ of Mueller-Hinton broth in each well. The samples were serially diluted and $50 \mu \mathrm{L}$ of bacterial Mueller-Hinton broth media adjusted to concentration 
of $1 / 100$ diluted McFarland $0.5 \%$ standard. The 96 -well was incubated for $24 \mathrm{~h}$ at $37{ }^{\circ} \mathrm{C}$. The minimum inhibitory concentration (MIC) values were determined as the concentration of compound that inhibits $50 \%$ of the growth of bacteria. The positive control showed the MIC values in the range of 0.1 to $1 \mu \mathrm{g} / \mathrm{mL}$. 
Table S1. NMR spectral data for Ansalactams B (1), C (2), and D (3) in methanol- $d_{4}{ }^{a}$

\begin{tabular}{|c|c|c|c|c|c|c|c|c|c|c|}
\hline \multirow[b]{2}{*}{ no. } & \multicolumn{2}{|r|}{1} & \multirow[b]{2}{*}{$\delta_{\mathrm{C}}$, mult. $^{\mathrm{b}}$} & \multicolumn{3}{|c|}{2} & \multicolumn{4}{|c|}{3} \\
\hline & $\delta_{\mathrm{C}}$, mult. $^{\mathrm{b}}$ & $\delta_{\mathrm{H}}($ mult, $J(\mathrm{~Hz}))$ & & $\delta_{\mathrm{H}}($ mult, $J(\mathrm{~Hz}))$ & COSY & HMBC & $\delta_{\mathrm{C}}$, mult. $^{\mathrm{b}}$ & $\delta_{\mathrm{H}}($ mult, $J(\mathrm{~Hz}))$ & COSY & HMBC \\
\hline 1 & $196.8, \mathrm{qC}$ & & 197.3, qC & & & & $191.9, \mathrm{qC}$ & & & \\
\hline 2 & $72.7, \mathrm{qC}$ & & $69.3, \mathrm{qC}$ & & & & $67.5, \mathrm{qC}$ & & & \\
\hline 3 & $69.7, \mathrm{CH}$ & 3.31 & $52.7, \mathrm{CH}_{2}$ & $2.25, \mathrm{~d}(11.4)$ & & $1,2,4,10,20,21$ & $47.9, \mathrm{CH}_{2}$ & $2.87, \mathrm{~d}(14.0)$ & & $1,2,3,4,10,21$ \\
\hline 4 & $1956, \mathrm{aC}$ & & $844 a C$ & 2.33, d (11.4) & & & $821 \mathrm{aC}$ & $2.23, \mathrm{~d}(14.0)$ & & \\
\hline 5 & $\begin{array}{l}195.0, \mathrm{qC} \\
128.0, \mathrm{qC}\end{array}$ & & $112.0, \mathrm{CH}$ & $6.88, \mathrm{~s}$ & & & $\begin{array}{l}02.1, \mathrm{CC} \\
121.4, \mathrm{gC}\end{array}$ & & & \\
\hline 6 & $167.8, \mathrm{qC}$ & & $162.0, \mathrm{qC}$ & & & & $165.8, \mathrm{qC}$ & & & \\
\hline 7 & $136.4, \mathrm{qC}$ & & $126.3, \mathrm{qC}$ & & & & $130.8, \mathrm{qC}$ & & & \\
\hline 8 & $131.5, \mathrm{CH}$ & $7.79, \mathrm{~s}$ & $131.0, \mathrm{CH}$ & $7.72, \mathrm{~s}$ & & $1,6,7,9,10$ & $136.3, \mathrm{CH}$ & $7.88, \mathrm{~s}$ & & $1,6,7,9,10$ \\
\hline 9 & $123.2, \mathrm{qC}$ & & 122.3, qC & & & & 124.6, qC & & & \\
\hline 10 & $140.1, \mathrm{qC}$ & & $151.0, \mathrm{qC}$ & & & & $150.8, \mathrm{qC}$ & & & \\
\hline 11 & $202.4, \mathrm{qC}$ & & 171.7, qC & & & & 201.6, qC & & & \\
\hline 12 & $141.0, \mathrm{qC}$ & & $130.1, \mathrm{qC}$ & & & & $88.1, \mathrm{qC}$ & & & \\
\hline 13 & $141.8, \mathrm{CH}$ & $6.39, \mathrm{~s}$ & $140.3, \mathrm{CH}$ & $7.27, \mathrm{~s}$ & & $11,12-\mathrm{Me}, 14-\mathrm{Me}$ & $68.6, \mathrm{CH}$ & $3.81, \mathrm{~s}$ & & $3,4,10,11,12,12-\mathrm{Me}, 14,15$ \\
\hline 14 & $134.7, \mathrm{qC}$ & & 132.3, qC & & & & $136.3, \mathrm{qC}$ & & & \\
\hline 15 & $135.9, \mathrm{CH}$ & 5.41, br s & 134.6, CH & $5.42, \mathrm{~d}(11.0)$ & 16 & 13, 14-Me, 16-Me, 17 & 141.6, CH & $5.77, \mathrm{~d}(4.2)$ & 16 & 16 \\
\hline 16 & $33.3, \mathrm{CH}$ & $2.97, \mathrm{~m}$ & $35.0, \mathrm{CH}$ & 3.31 & $15,16-\mathrm{Me}, 17$ & $16-\mathrm{Me}$ & $34.0, \mathrm{CH}$ & $3.41, \mathrm{~m}$ & 15,17 & $15,16-\mathrm{Me}$ \\
\hline 17 & $134.5, \mathrm{CH}$ & $4.77, \mathrm{~d}(8.0)$ & $143.8, \mathrm{CH}$ & $6.73, \mathrm{~d}(11.0)$ & 16 & $15,16,18-\mathrm{Me}, 19$ & $148.8, \mathrm{CH}$ & $6.24, \mathrm{~d}(10.0)$ & 16 & 15,19 \\
\hline 18 & $136.5, \mathrm{qC}$ & & $135.0, \mathrm{qC}$ & & & & $130.8, \mathrm{qC}$ & & & \\
\hline 19 & $92.3, \mathrm{qC}$ & & $207.5, \mathrm{qC}$ & & & & $202.7, \mathrm{qC}$ & & & \\
\hline 20 & $43.1, \mathrm{CH}$ & $2.47, \mathrm{qd}(6.8,4.3)$ & $63.3, \mathrm{qC}$ & & & & $47.5, \mathrm{CH}$ & $3.23, \mathrm{qd}(6.8,3.4)$ & $20-\mathrm{Me}, 21$ & 20-Me \\
\hline 21 & $59.2, \mathrm{CH}$ & 2.53 dd $(9.0,4.3)$ & $53.4, \mathrm{CH}$ & 3.31 & 22 & $1,2,3,4,19$ & 54.7, $\mathrm{CH}$ & 2.43 , dd $(6.8,3.4)$ & 20,22 & $3,20,23$ \\
\hline 22 & $43.4, \mathrm{CH}$ & 2.87 , dt $(9.0,4.5)$ & $43.1, \mathrm{CH}$ & $2.53, \mathrm{~m}$ & 21,24 & & $48.7, \mathrm{CH}$ & 2.59, ddd $(14.0,4.5,2.4)$ & 21,24 & 23,24 \\
\hline 23 & $183.8, \mathrm{qC}$ & & $181.3, \mathrm{qC}$ & & & & $186.4, \mathrm{qC}$ & & & \\
\hline 24 & $45.4, \mathrm{CH}_{2}$ & $1.61, \mathrm{~m}$ & $43.6, \mathrm{CH}_{2}$ & $1.56, \mathrm{~m}$ & 22,25 & $22,23,25$ & $45.6, \mathrm{CH}_{2}$ & $1.84, \mathrm{~m}$ & 22,25 & 22,25 \\
\hline & & $1.26, \mathrm{~m}$ & & $1.16, \mathrm{~m}$ & & & & $1.69, \mathrm{~m}$ & & \\
\hline 25 & $26.2, \mathrm{CH}$ & $1.78, \mathrm{~m}$ & $25.1, \mathrm{CH}$ & $1.41, \mathrm{~m}$ & $24,26,27$ & & $27.7, \mathrm{CH}$ & $1.99, \mathrm{~m}$ & $24,26,27$ & $22,24,26,27$ \\
\hline 26 & $23.8, \mathrm{CH}_{3}$ & $0.94, \mathrm{~d}(6.8)$ & $23.7, \mathrm{CH}_{3}$ & $0.82, \mathrm{~d}(6.8)$ & 25 & $24,25,27$ & $22.1, \mathrm{CH}_{3}$ & $1.05, \mathrm{~d}(6.8)$ & 25 & $24,25,27$ \\
\hline 27 & $22.5, \mathrm{CH}_{3}$ & $0.92, \mathrm{~d}(6.8)$ & $22.1, \mathrm{CH}_{3}$ & $0.80, \mathrm{~d}(6.8)$ & 25 & $24,25,26$ & $23.8, \mathrm{CH}_{3}$ & $1.15, \mathrm{~d}(6.8)$ & 25 & $24,25,26$ \\
\hline 7-Me & $17.5, \mathrm{CH}_{3}$ & $2.30, \mathrm{~s}$ & $16.0, \mathrm{CH}_{3}$ & $2.18, \mathrm{~s}$ & & $6,7,8$ & $15.1, \mathrm{CH}_{3}$ & $2.33, \mathrm{~s}$ & & $6,7,8$ \\
\hline $12-\mathrm{Me}$ & $13.3, \mathrm{CH}_{3}$ & $1.87, \mathrm{~s}$ & $14.3, \mathrm{CH}_{3}$ & $1.85, \mathrm{~s}$ & & 11,13 & $14.8, \mathrm{CH}_{3}$ & $1.57, \mathrm{~s}$ & & $11,12,13$ \\
\hline 14-Me & $23.3, \mathrm{CH}_{3}$ & $1.69, \mathrm{~s}$ & $23.0, \mathrm{CH}_{3}$ & $1.88, \mathrm{~s}$ & & 13,15 & $20.3, \mathrm{CH}_{3}$ & $2.38, \mathrm{~s}$ & & $13,14,15$ \\
\hline $16-\mathrm{Me}$ & $21.9, \mathrm{CH}_{3}$ & $1.09, \mathrm{~d}(6.8)$ & $20.7, \mathrm{CH}_{3}$ & $1.17, \mathrm{~d}(7.0)$ & 16 & $15,16,17$ & $19.3, \mathrm{CH}_{3}$ & $1.16, \mathrm{~d}(6.8)$ & 16 & $15,16,17$ \\
\hline 18-Me & $14.8, \mathrm{CH}_{3}$ & $1.74, \mathrm{~s}$ & $13.9, \mathrm{CH}_{3}$ & $1.60, \mathrm{~s}$ & & 17,19 & $10.8, \mathrm{CH}_{3}$ & $0.79, \mathrm{~s}$ & & $17,18,19$ \\
\hline 20-Me & $11.0, \mathrm{CH}_{3}$ & $0.95, \mathrm{~d}(6.8)$ & $20.3, \mathrm{CH}_{3}$ & $1.59, \mathrm{~s}$ & & $4,19,20,21$ & $8.3, \mathrm{CH}_{3}$ & $1.07, \mathrm{~d}(6.9)$ & 20 & $19,20,21$ \\
\hline
\end{tabular}


Figure S1. Key COSY and HMBC correlations for planar structure of ansalactam C (2)

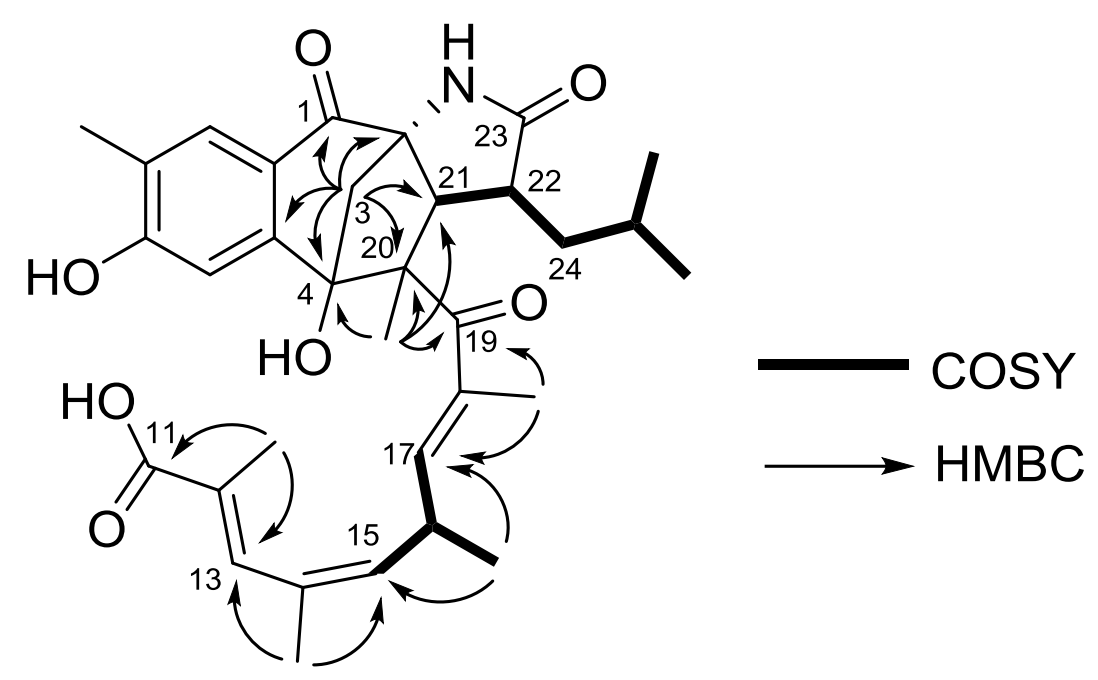


Figure S2. Key ROESY correlations for determination of the relative stereochemistry of $\mathbf{2}$ (a) and $\mathbf{3}$ (b)

a)

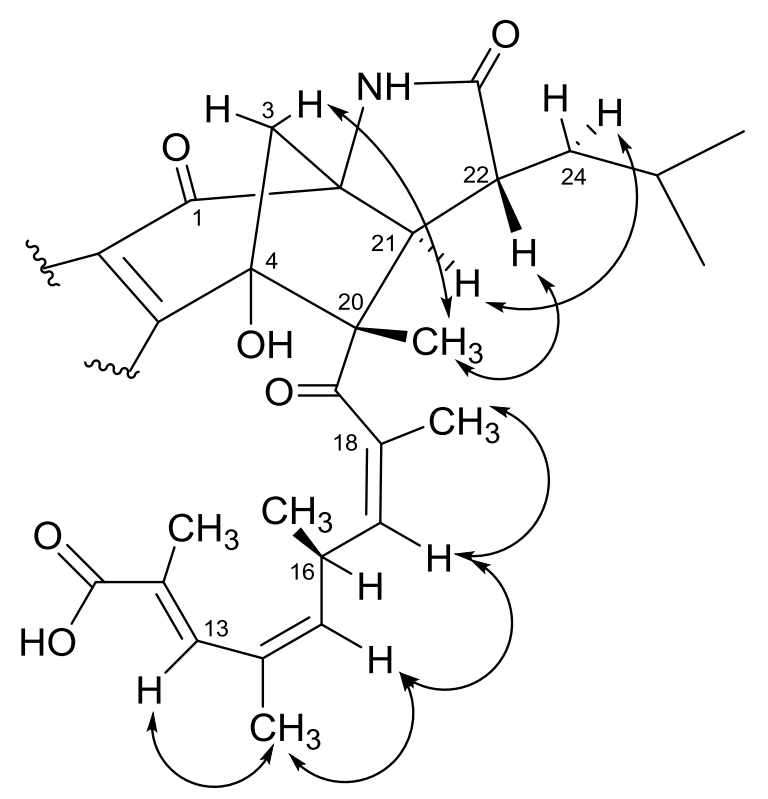

b)

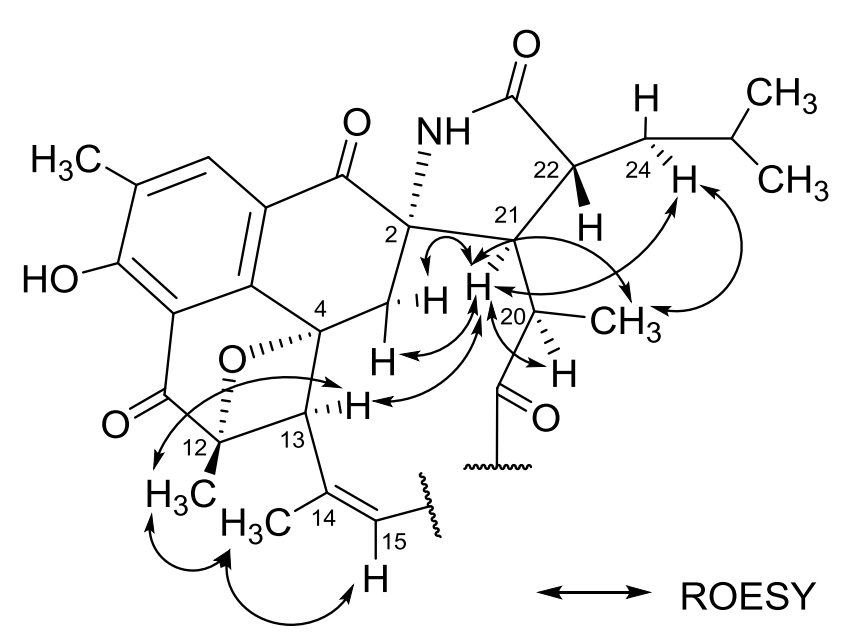


Figure S3. ${ }^{1} \mathrm{H}$ NMR Spectrum (600 MHz) of Ansalactam B (1) in Methanol- $d_{4}$

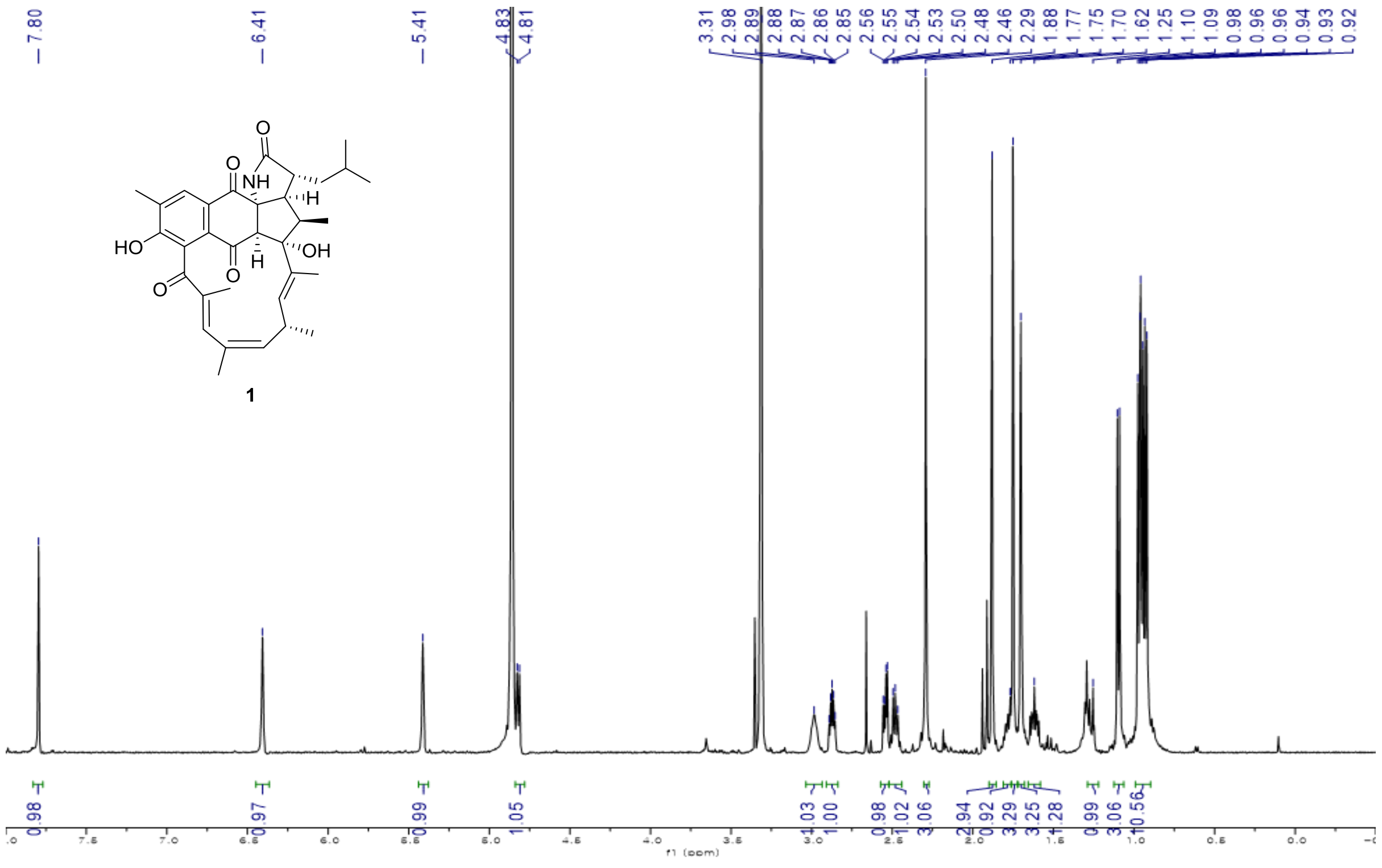


Figure S4. ${ }^{13} \mathrm{C}$ NMR Spectrum (75 MHz) of Ansalactam B (1) in Methanol- $d_{4}$

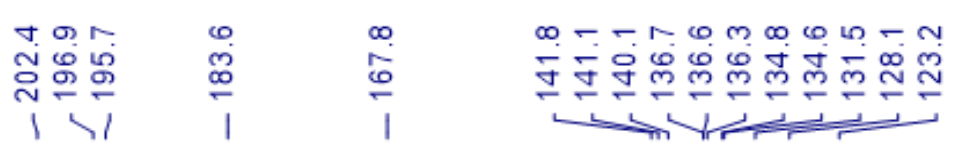

ஸे
।

$\begin{array}{cc}-\infty & \\ 0 & 0 \\ 1 & 1\end{array}$

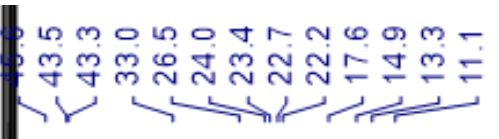

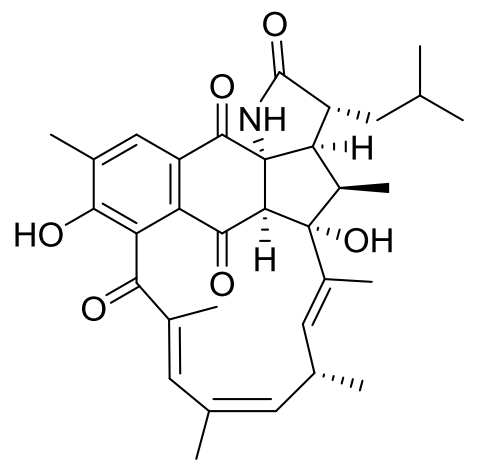

1
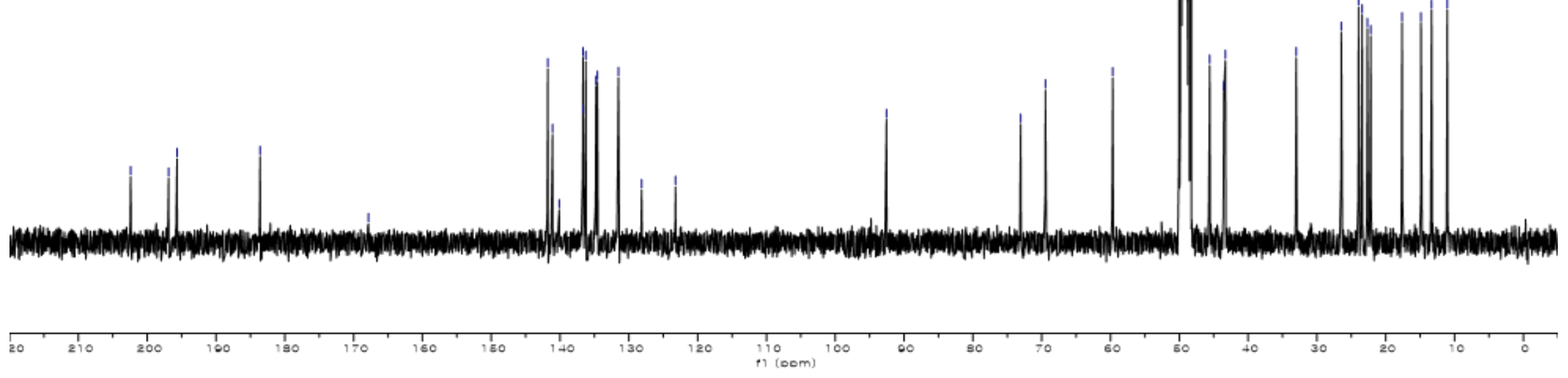

Si 1 
Figure S5. gCOSY Spectra (600 MHz) of Ansalactam B (1) in Methanol- $d_{4}$

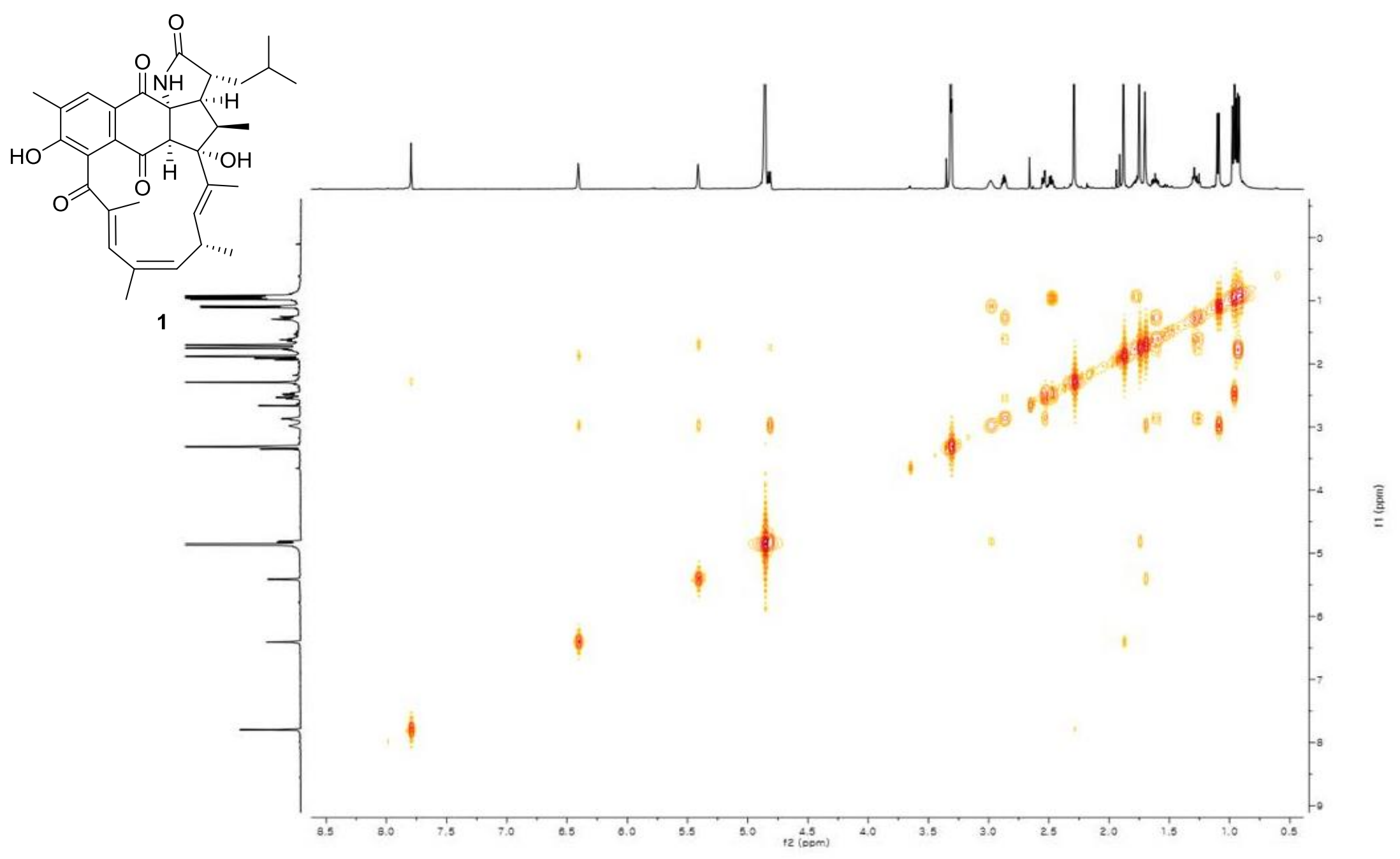


Figure S6. gHSQC Spectra (600 MHz) of Ansalactam B (1) in Methanol- $d_{4}$

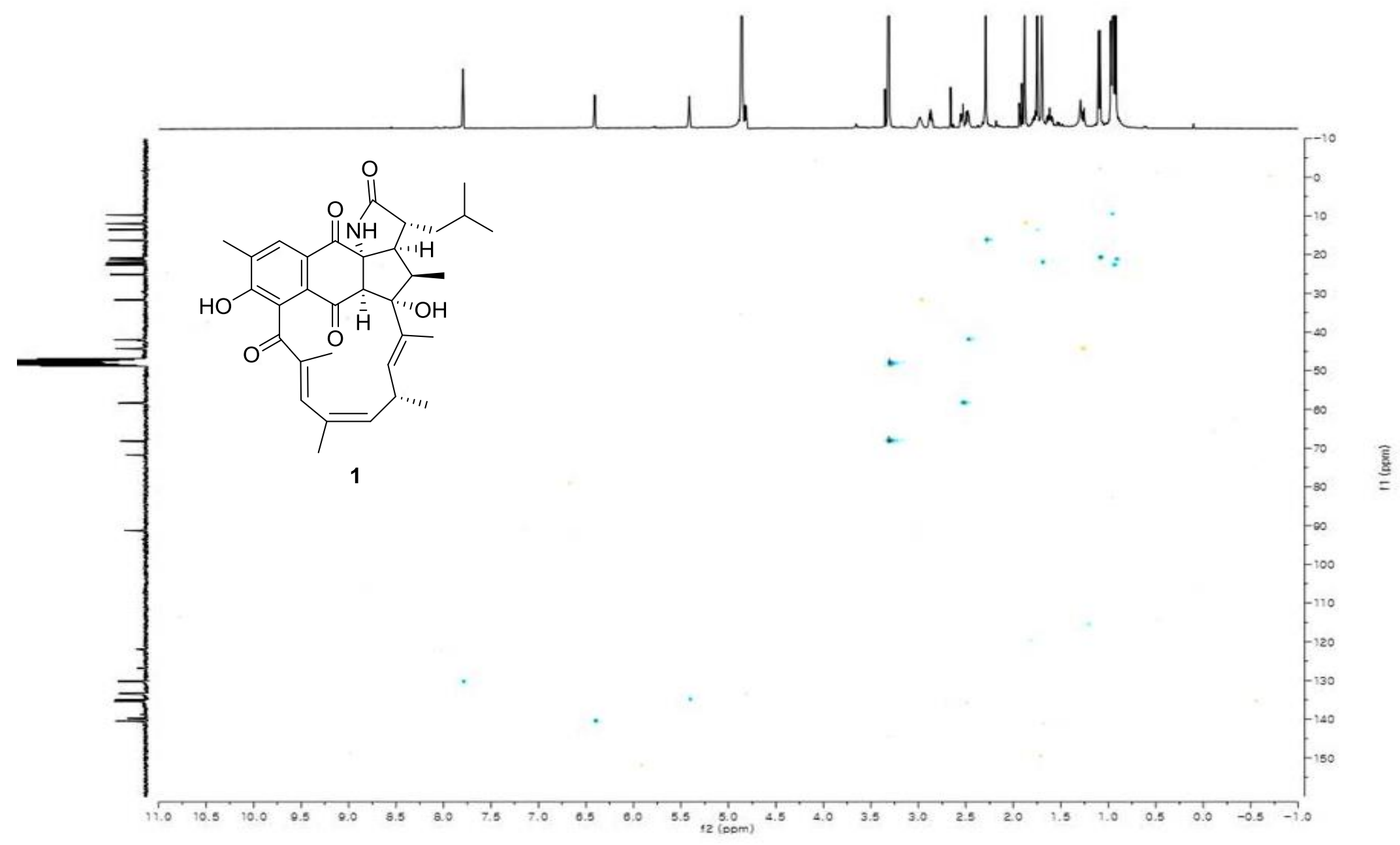


Figure S7. gHMBC Spectra $(600 \mathrm{MHz})$ of Ansalactam B (1) in Methanol- $d_{4}$

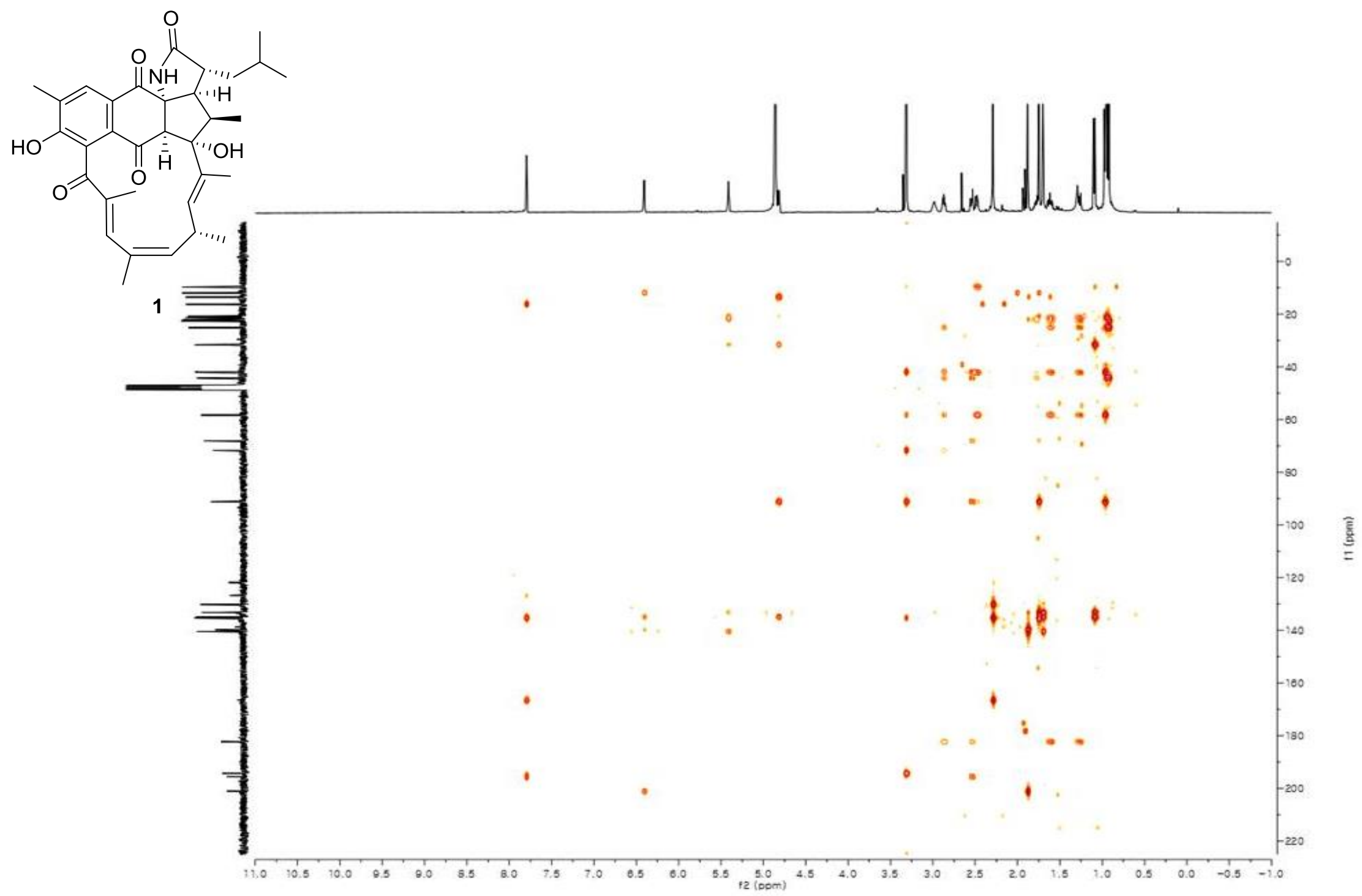


Figure S8. ROESY Spectra (600 MHz) of Ansalactam B (1) in Methanol- $d_{4}$

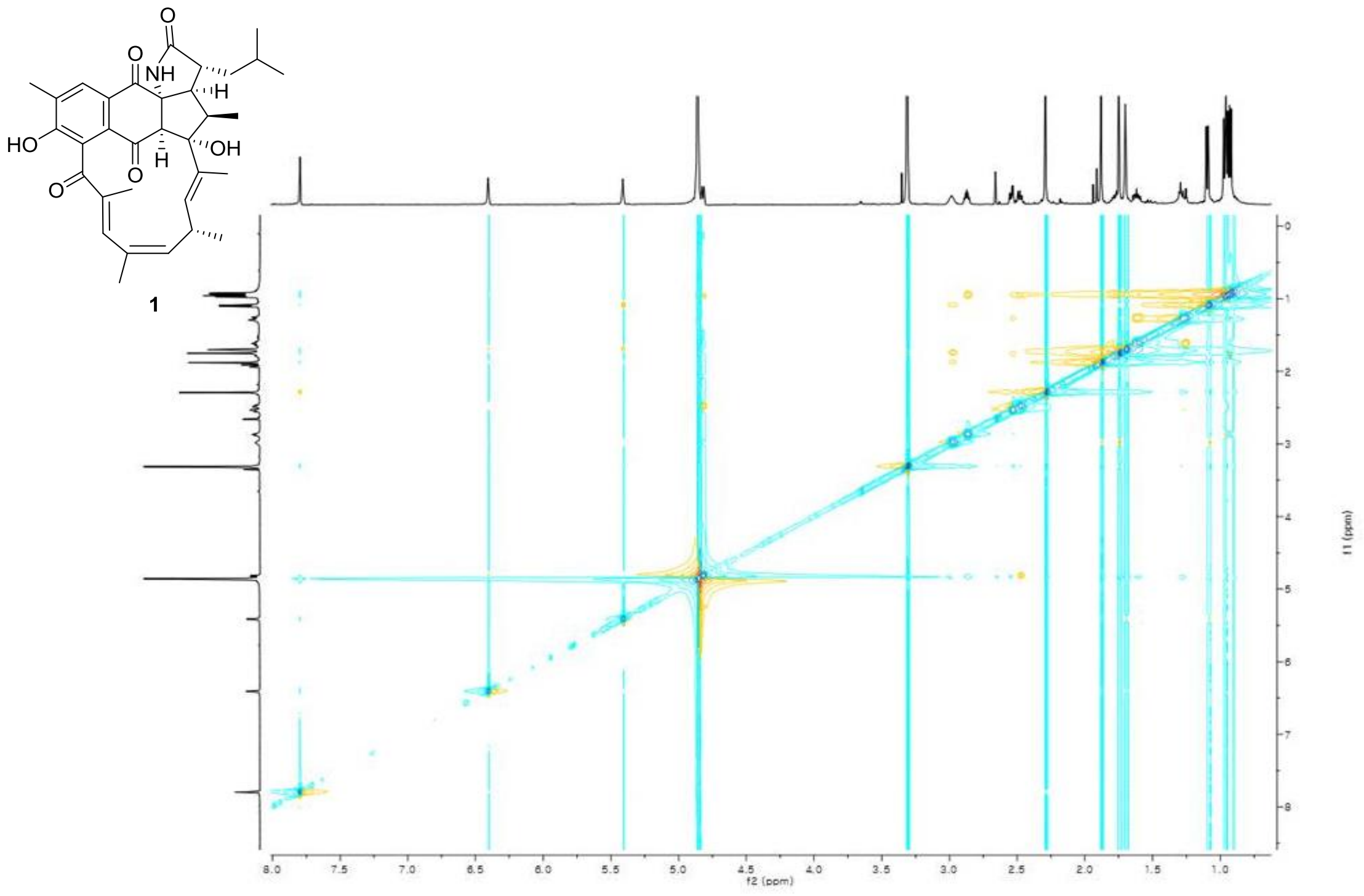

S15 
Figure S9. ${ }^{1} \mathrm{H}$ NMR Spectrum $(600 \mathrm{MHz})$ of Ansalactam C (2) in Methanol- $d_{4}$

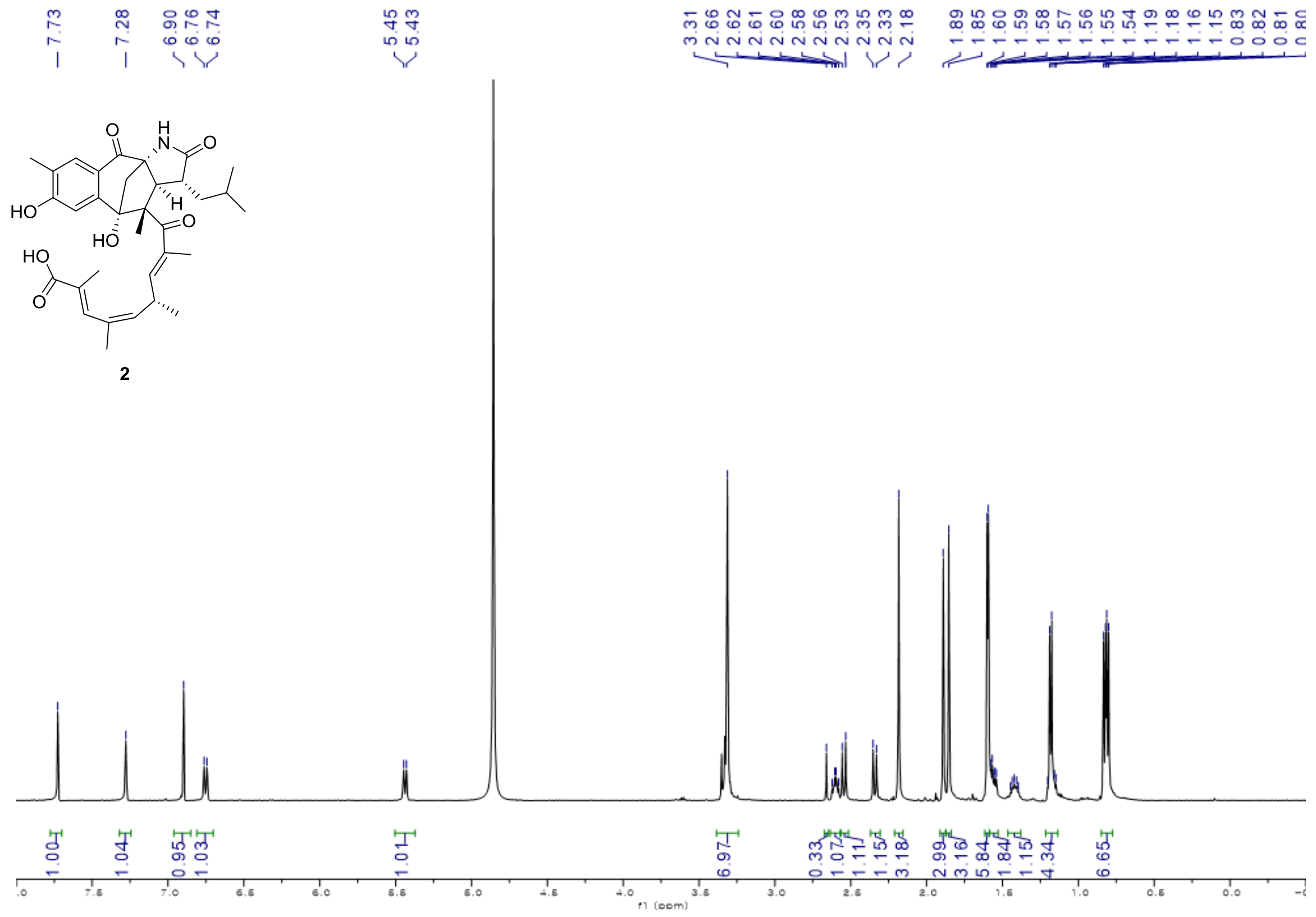


Figure S10. ${ }^{13} \mathrm{C}$ NMR Spectrum $(75 \mathrm{MHz})$ of Ansalactam C (2) in Methanol- $d_{4}$

苛

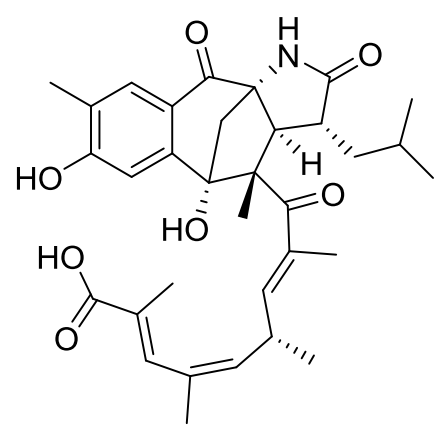

2 $\circ$
$\infty$
।

i

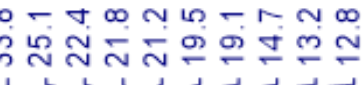

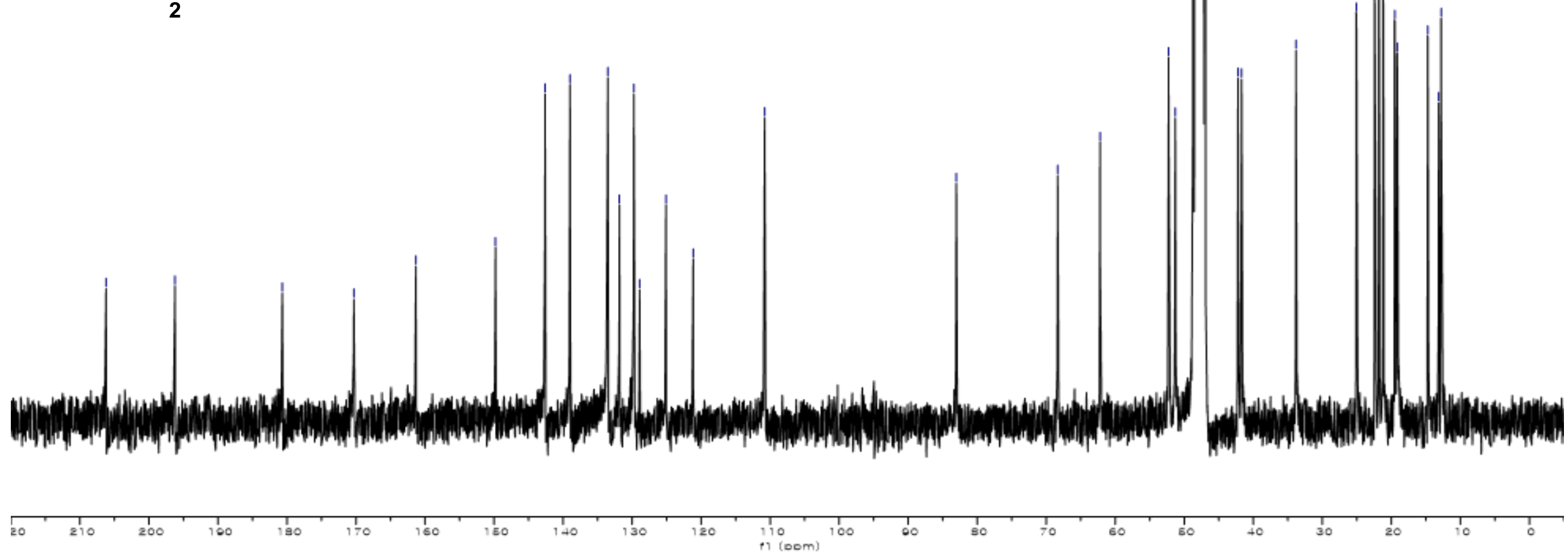

S17 


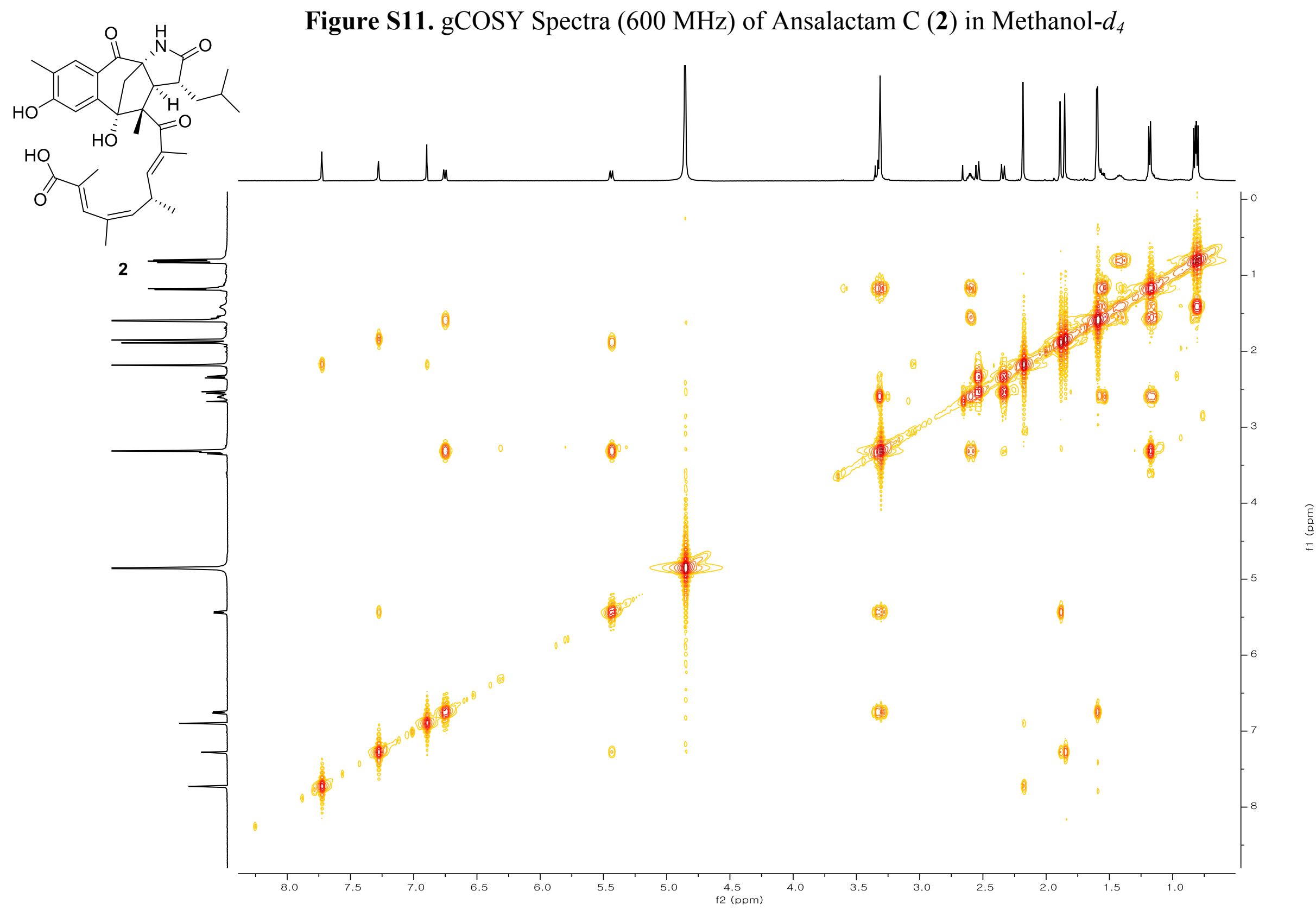




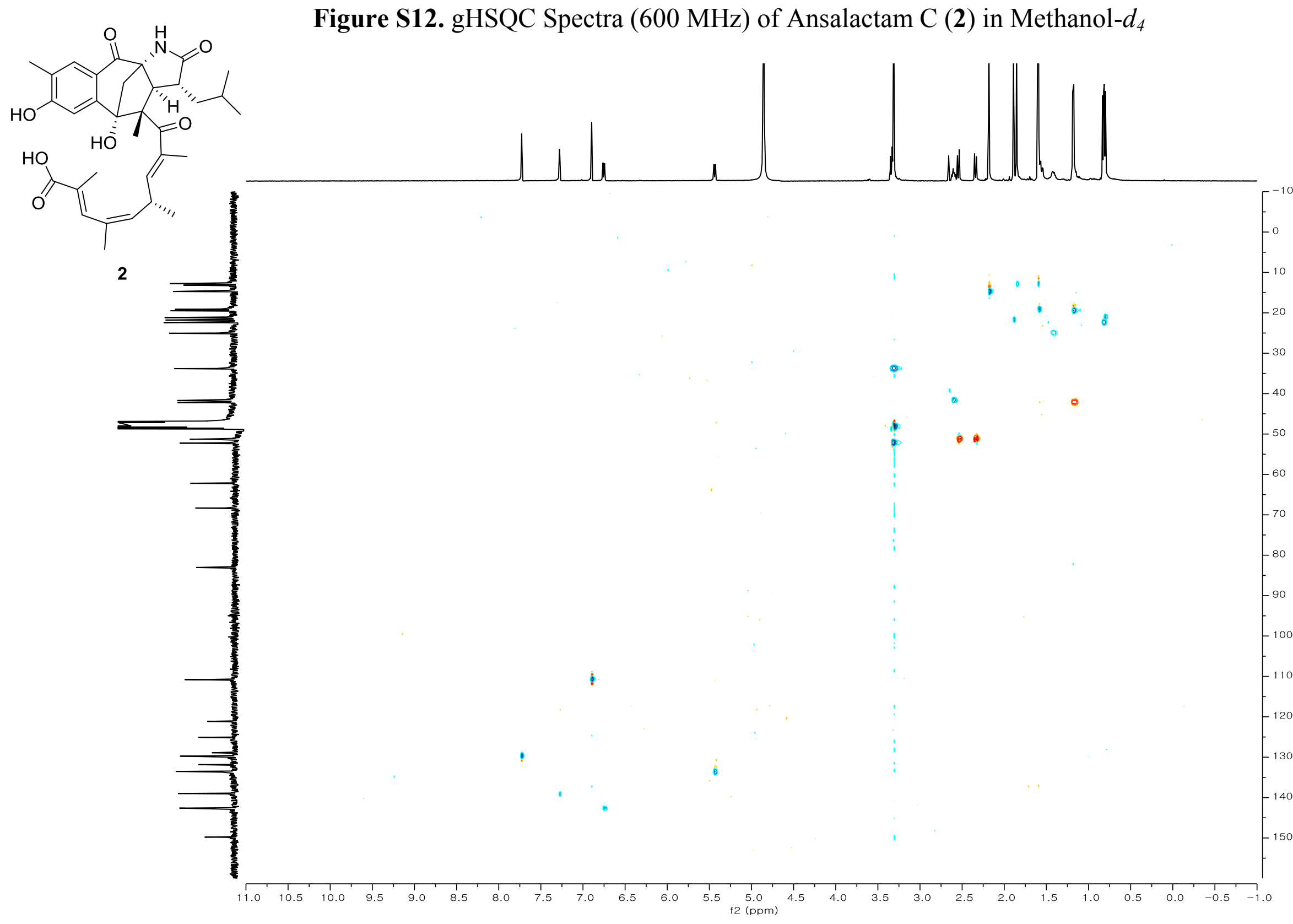


Figure S13. gHMBC Spectra (600 MHz) of Ansalactam C (2) in Methanol- $d_{4}$

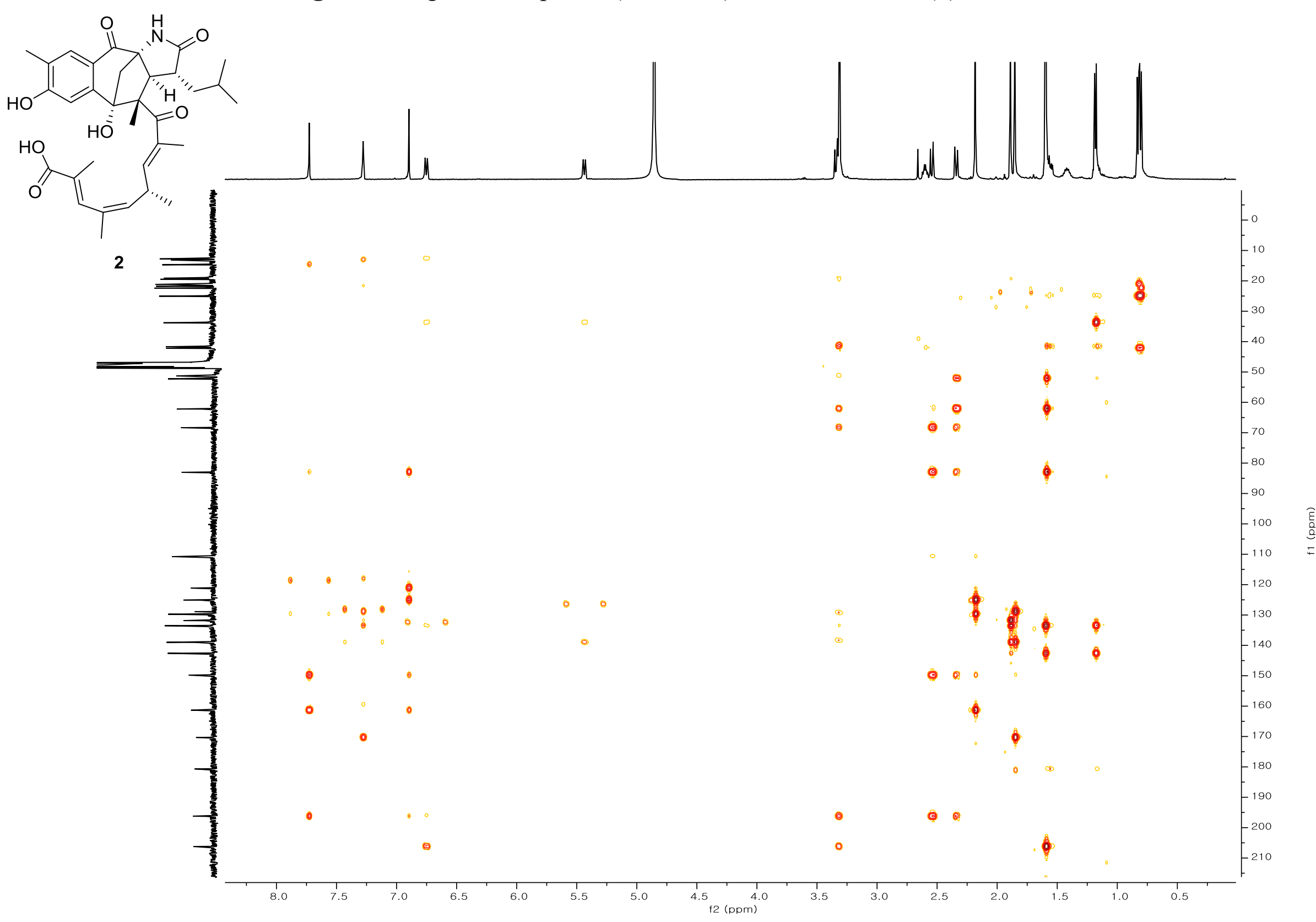


Figure S14. ROESY Spectra (600 MHz) of Ansalactam C (2) in Methanol- $d_{4}$

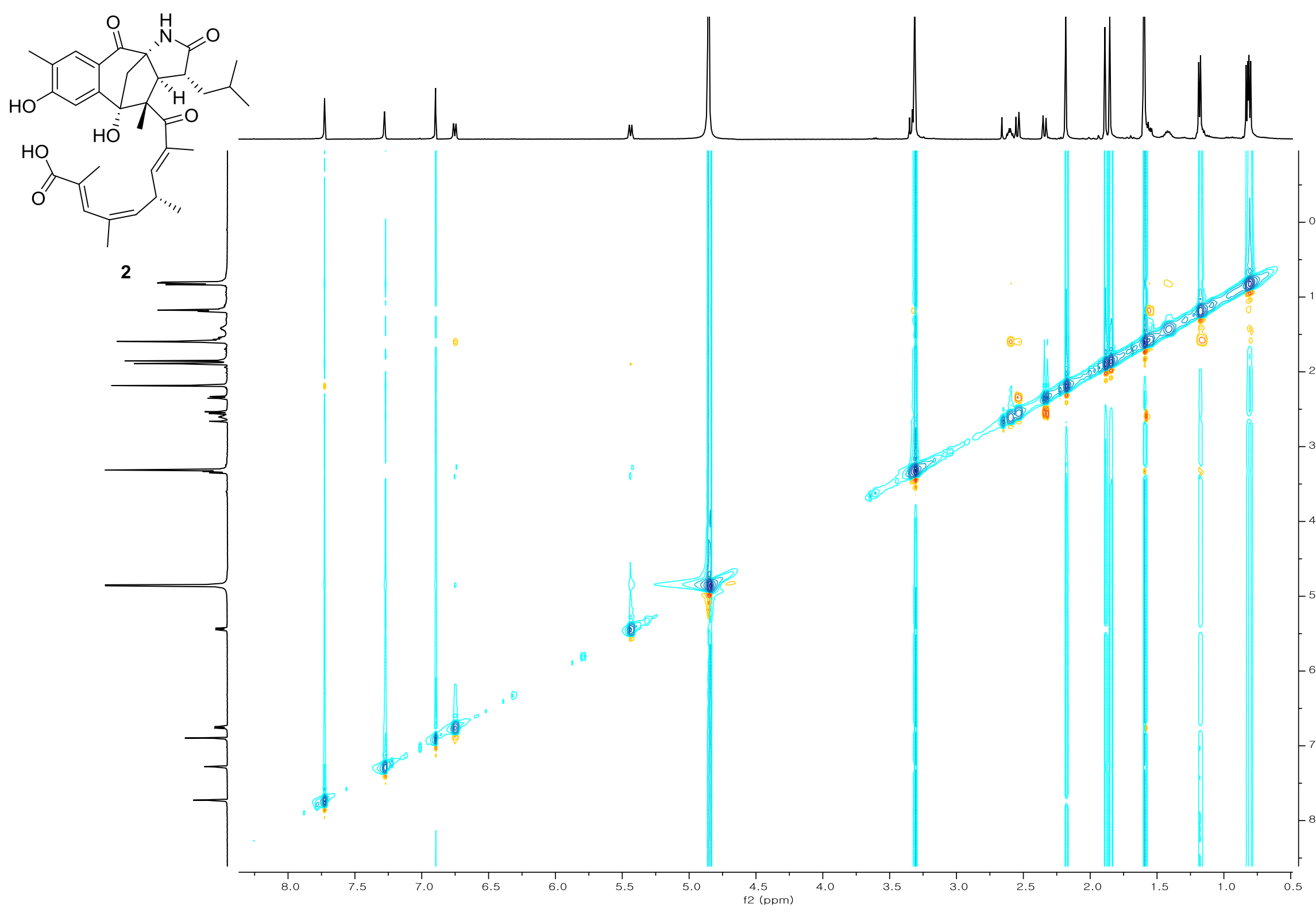


Figure S15. ${ }^{1} \mathrm{H}$ NMR Spectrum (600 MHz) of Ansalactam D (3) in Methanol- $d_{4}$

$\stackrel{\infty}{\sim} \stackrel{\sim}{\sim} \stackrel{\sim}{\sim}$

( )

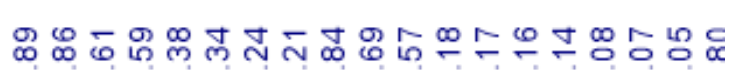

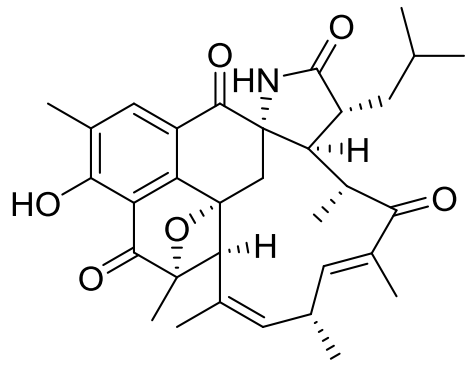

3
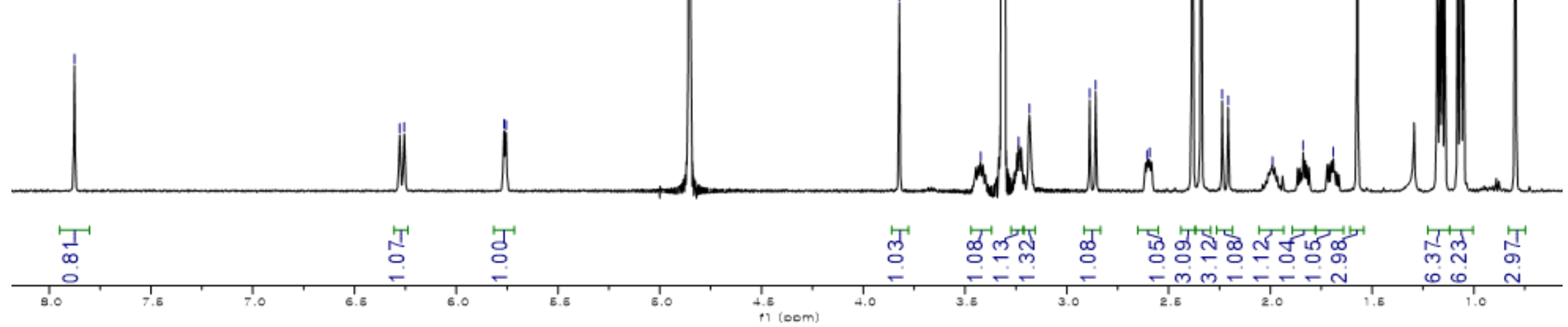
Figure S16. ${ }^{13} \mathrm{C}$ NMR Spectrum $(75 \mathrm{MHz})$ of Ansalactam D (3) in Methanol- $d_{4}$

ஸे

$\infty$

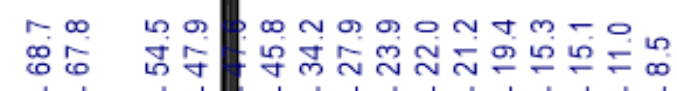

$\begin{array}{lll}1 & 1\end{array}$

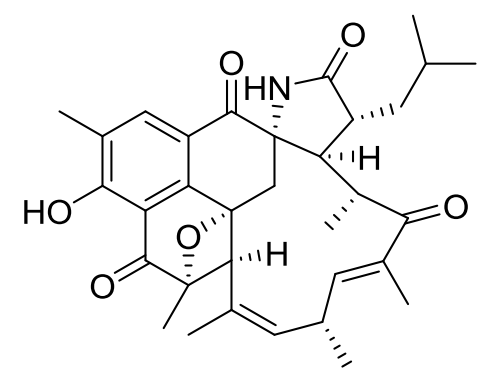

3
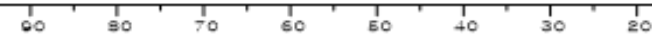


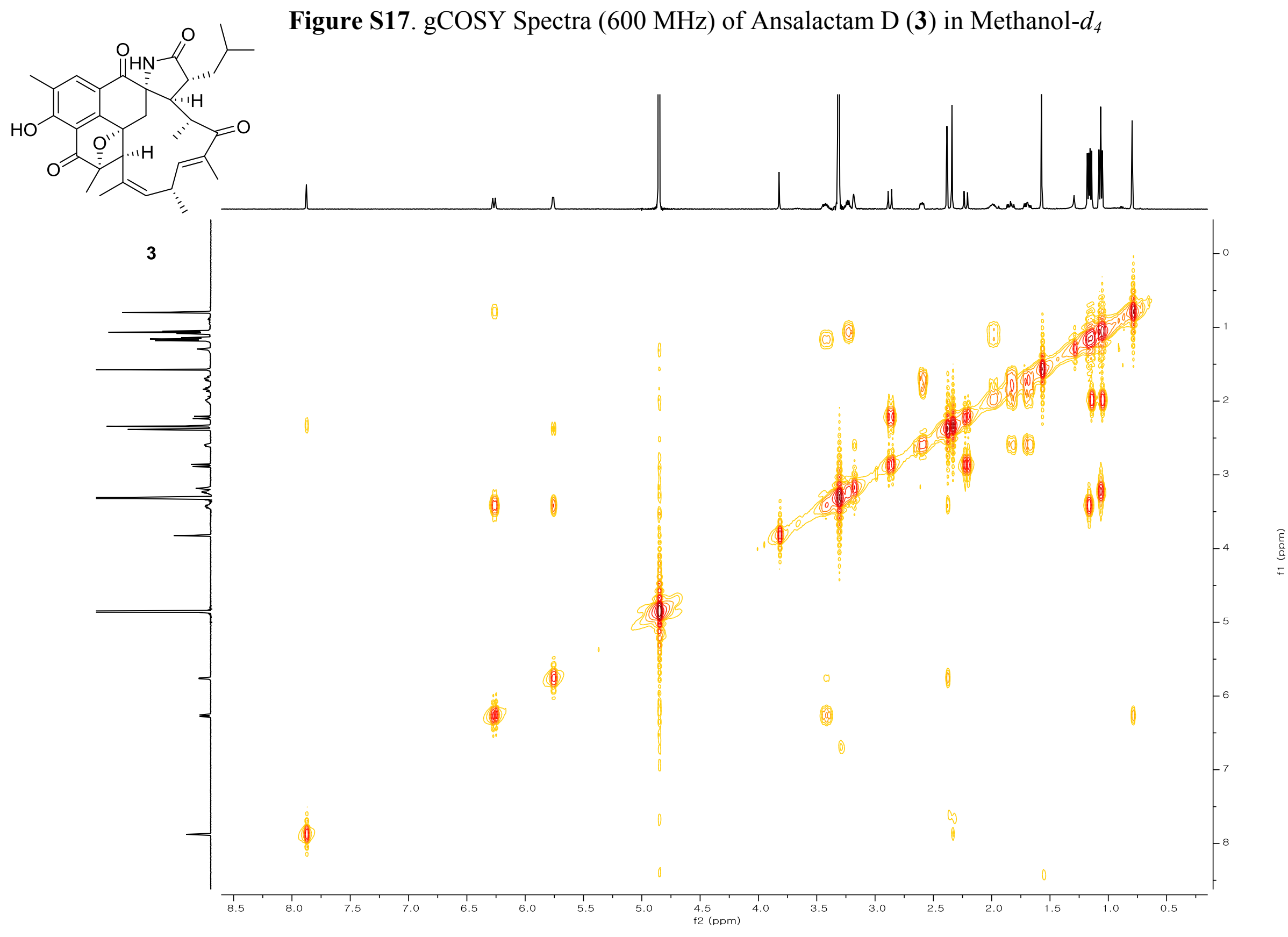


Figure S18. gHSQC Spectra $(600 \mathrm{MHz})$ of Ansalactam D (3) in Methanol- $d_{4}$

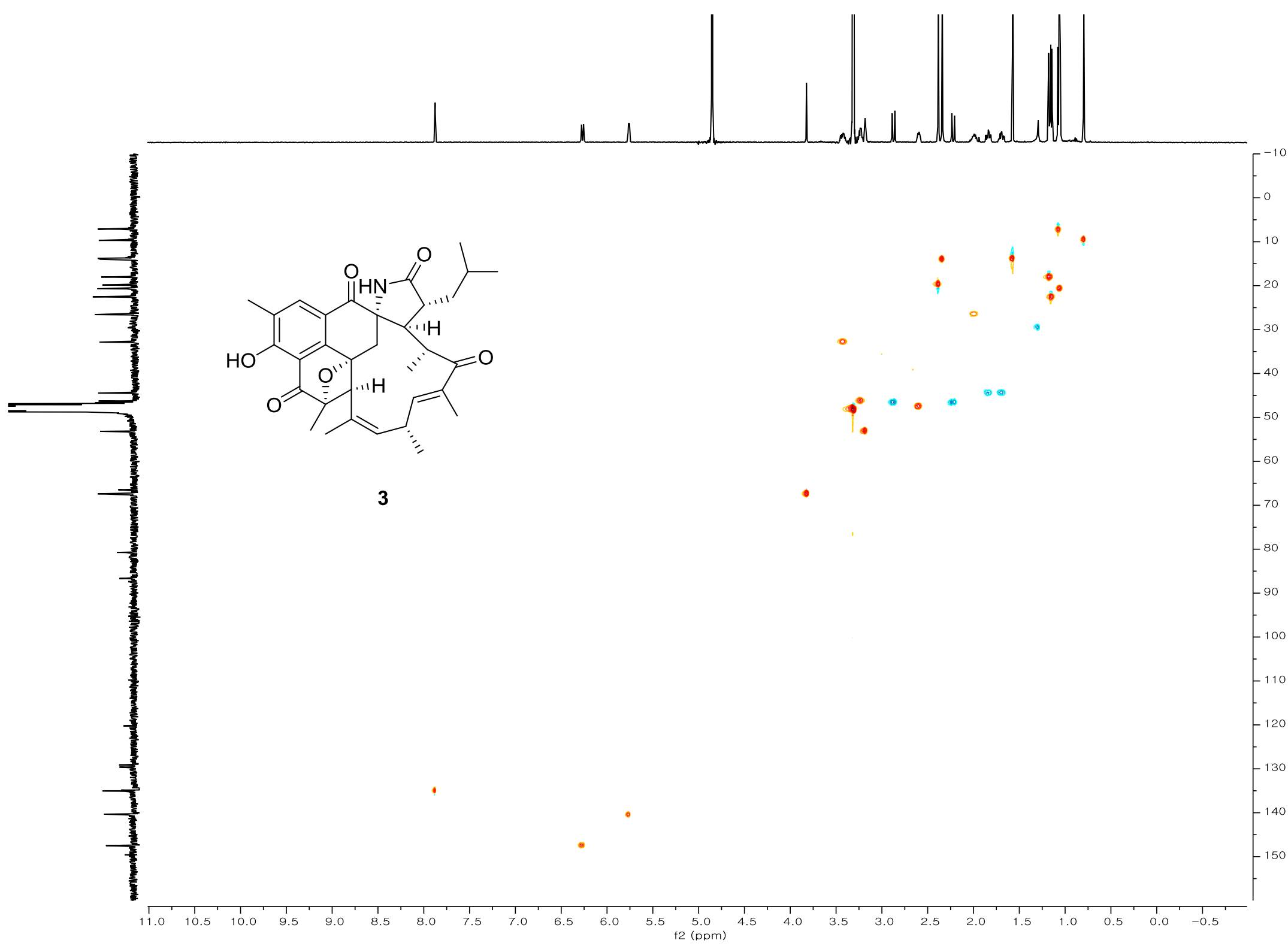


Figure S19. gHMBC Spectra $(600 \mathrm{MHz})$ of Ansalactam D (3) in Methanol- $d_{4}$

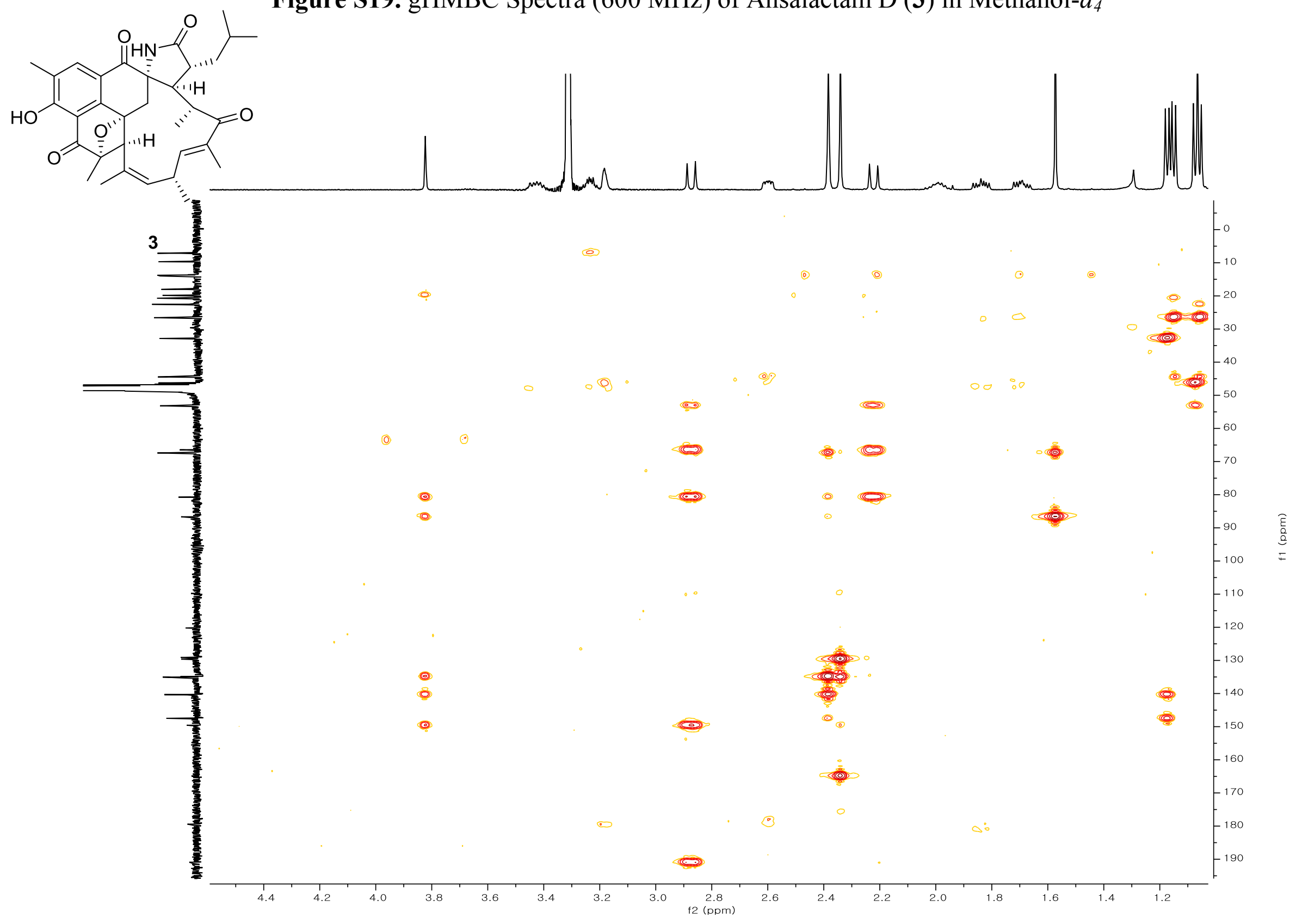




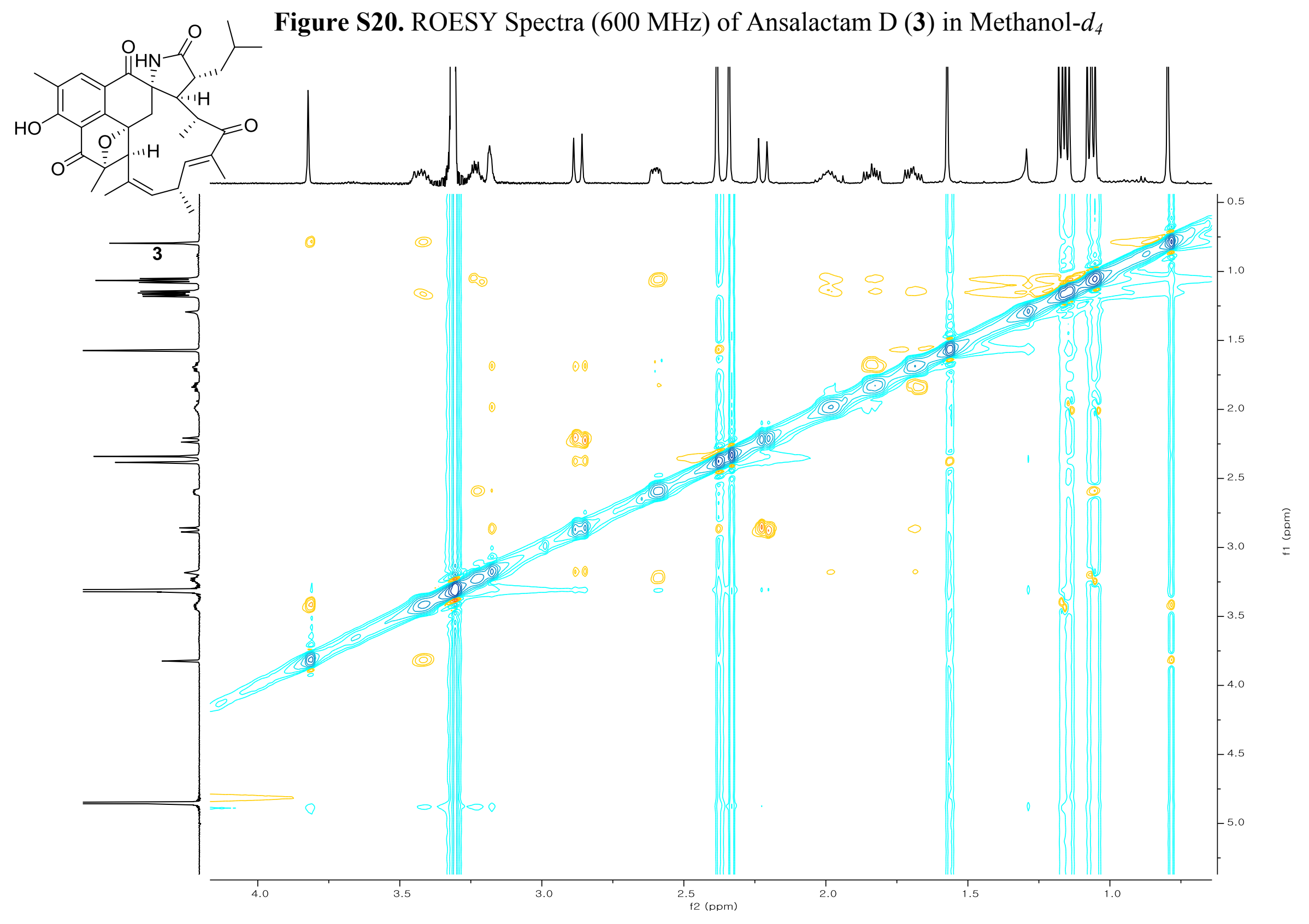


Figure S21. Energy-minimized model of ansalactam B (1) (calculated by Chem3D ver 15.0, red = oxygen, white $=$ hydrogen, gray $=$ carbon, pink $=$ lone pair, double solid arrow $=$ ROESY correlation), Upper arrow depicted ROESY correlation between H-22 and $20 \mathrm{Me}$ at beta side of the ring. Lower arrow depicts ROESY between H-3 / H-21 / H-20 at alpha side of the ring

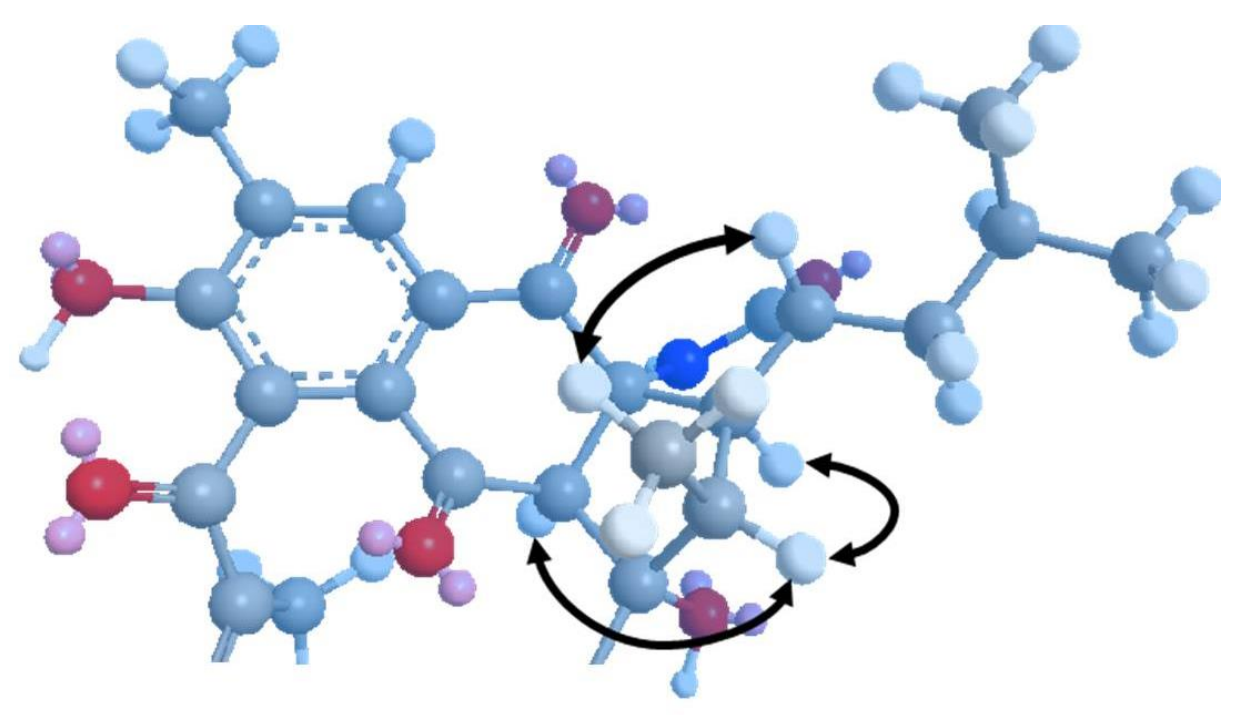


Figure S22. Energy minimized model of ansalactam D (3) a) model of beta $O$ ether, b) model of alpha O ether between C-4 / C-20 (calculated by Chem3D ver 15.0, red $=$ oxygen, white $=$ hydrogen, gray $=$ carbon, pink $=$ lone pair, double solid arrow $=$ ROESY correlation)
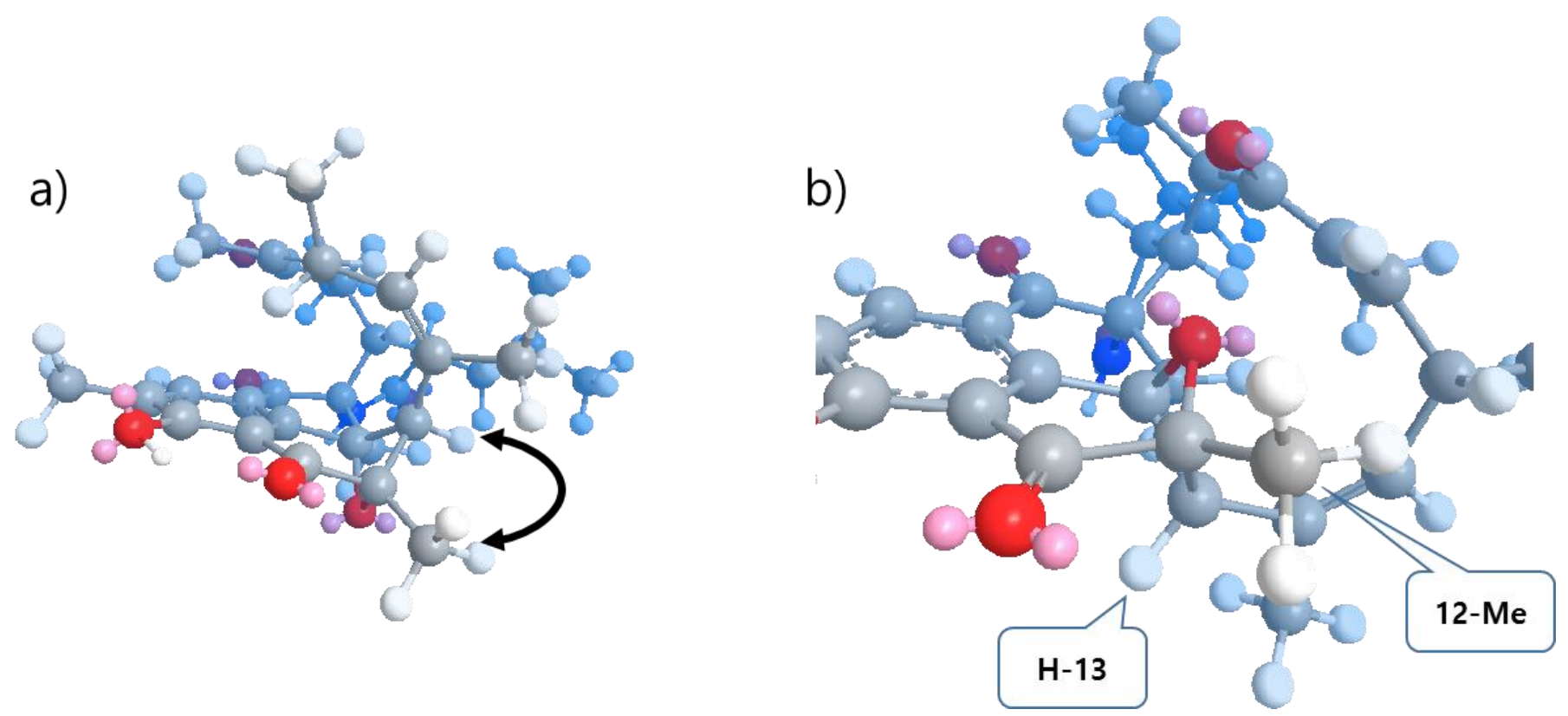